${ }^{1}$ Graduate Program in Dentistry, Cruzeiro do Sul University, São Paulo, SP, Brazil.

${ }^{2}$ Camilo Castelo Branco University, São Paulo, SP, Brazil. ${ }^{3}$ Department of Biomaterials and Oral Biology, School of Dentistry, University of São Paulo (USP), São Paulo, Brazil.
Corresponding author:

Ângela Toshie Araki

Av Robert Kennedy 2126/sala 4,

ZIP CODE 09861-080 -

São Bernardo do Campo, SP Brazil

Tel.: +55-11-992534078

Fax: +55-11-43921575

a_araki@me.com

Editor: Altair A. Del Bel Cury

Received: December 29, 2020

Accepted: August 12, 2021

\section{Effect of intracanal diode laser irradiation on fracture resistance of roots restored with CAD/CAM posts}

\author{
Flavia Florentino Teixeira da Silva ${ }^{1}$ (D), André Hayato \\ Saguchi ${ }^{1}$ (D), Sidnea Aparecida Freitas Paiva ${ }^{1}$ (D), \\ Guilherme Espósito Pires ${ }^{1}$ (D), Mariana Isidoro ${ }^{1}$ (D), \\ Aldo Brugnera Junior ${ }^{2}$ (D), Paulo Francisco Cesar $^{3}$ (D), \\ Ângela Toshie Araki ${ }^{1 *}$ (D)
}

Aim: To evaluate the fracture resistance of roots restored with CAD/CAM-fabricated posts, receiving or not intracanal laser treatment, compared with glass fiber posts under mechanical cycling. Methods: Twenty-seven endodontically treated, single-rooted teeth were divided into 3 groups: group 1 (control), prefabricated glass fiber posts relined with resin composite; group 2, CAD/CAM-fabricated intraradicular posts using Resin Nano Ceramic (RNC) blocks; and group 3, CAD/CAM-fabricated intraradicular posts using RNC blocks in canals irradiated with a 940-nm diode laser (100 mJ, 300-um optic fiber, coronal-apical and apical-coronal helical movements, speed of $2 \mathrm{~mm} / \mathrm{second}$, 4 times each canal). After cementation of the coping, cyclic loading was applied at an angle of $135^{\circ}$ to the long axis of the root, with a pulse load of $130 \mathrm{~N}$, frequency of $2.2 \mathrm{~Hz}$, and 150,000 pulses on the crown at a point located $2 \mathrm{~mm}$ below the incisal edge on the lingual aspect of the specimen. Every 50,000 cycles, the specimens were evaluated for root fracture occurring below or above the simulated bone crest. Results were analyzed by one-way ANOVA followed by Tukey's test $(p<0.05)$. Results: Group 1 was the least resistant, while groups 2 and 3 were the most resistant. Group 1 differed significantly from groups 2 and $3(p<0.01)$, but there was no difference between groups 2 and $3(p<0.01)$. Conclusion: Treatment of the intracanal surface with diode laser had no influence on fracture resistance of roots restored with CAD/CAM-fabricated posts, but a longer cycling time is required to evaluate the real benefits of diode laser irradiation.

Keywords: Lasers. Endodontics. Dentistry. Computer-aided design. 


\section{Introduction}

Endodontically treated teeth are at increased risk of fracture due to loss of healthy tooth structure, which may result from inadequate access cavity preparation, carious lesions, and/or extensive restorations ${ }^{1}$. In order to improve crown retention and stress distribution on the remaining tooth structure, the use of intraradicular posts fabricated from different materials is indicated ${ }^{2}$.

Metal alloys are the oldest materials, but their high modulus of elasticity (100-200GPa) is much higher than the dentin (18GPa), what can lead to root fracture. In contrast, prefabricated carbon and glass fiber posts have a lower modulus of elasticity-similar to dentin- and are presented in different diameters and tapers. Even when the most adjustable post to the prepared root canal is selected, the film thickness of the luting cement may be higher, which reduces fracture resistance ${ }^{3}$. With the development of the CAD/CAM system, intraradicular posts can replace the intracanal and coronal portions in one piece, thus reducing the resin-cement interface, shortening clinical time, and enhancing adaptation ${ }^{4}$.

Recent studies have shown that CAD/CAM-fabricated intraradicular posts increase root fracture resistance, providing an alternative to the use of prefabricated and cast metal posts ${ }^{5}$. An in vitro study ${ }^{6}$ compared the fracture resistance of flared canals restored with CAD/CAM post- and -core with prefabricated glass fiber and cast gold alloy posts. Radicular fractures occurred in all 3 groups. However, CAD/CAM post-and -core reduced the occurrence fractures in the middle and in apical 1/3 part of root. Fractures in those regions are irreparable and, consequently, catastrophic to root survival ${ }^{6}$.

Debonding of posts to the dentin wall is a currently concern. Despite the promising results obtained with CAD/CAM fabricated intraradicular posts regarding to fracture resistance of root canals, there is no protocol for post surface treatment that ensures better adhesion to the dentin. Simple procedures are indicated, such as use of $70 \%$ alcohol during cleaning of the posts and use of an universal adhesive. Different surface treatments of CAD/CAM glass fiber posts with $24 \%$ hydrogen peroxide and a moisture of silane and ethanol solution did not influence in bond strength values ${ }^{7,8}$.

The bonding quality can be influenced by the type of dentin and the presence of smear layer produced during chemomechanical preparation ${ }^{9,10}$. Smear layer can be removed by using suitable chemical substances and high-power lasers ${ }^{11-16}$

Studies testing fracture resistance of roots after dentin pretreatment using diode lasers and luting a CAD/CAM post are scarce, especially using resin nanoceramic CAD/CAM blocks- Lava ${ }^{\text {iM }}$ Ultimate CAD / CAM Restorative, 3M ESPE, USA which have, according to the manufacturer, a modulus of elasticity $(12,8 \mathrm{GPa})$ similar to the dentin $(18 \mathrm{GPa})$. In view of this scenario, it seems pertinent to evaluate the fracture resistance of roots restored with CAD/CAM-fabricated intraradicular posts made from Lava ${ }^{\mathrm{TM}}$ Ultimate blocks, receiving or not intracanal treatment with high-power diode laser, compared with glass fiber posts relined with resin composite under mechanical cycling. 


\section{Materials and Methods}

\section{Specimen selection and preparation}

Twenty-seven single-rooted human permanent teeth without fractures, cracks, or fissures were obtained by donation from the human tooth bank of APCD São Caetano do Sul, São Paulo, Brazil. The sample size was based on previous studies ${ }^{6,7}$ that used 10 samples per group. In our study, 9 specimens were used, as there was a loss of 3 samples in the preparation (considering a significance level of $5 \%$, we had a power of 0.77 to detect differences between groups with specimen rates of $25 \%$ and $85 \%$, respectively). The crowns were removed with a carborundum disc, leaving a root length of $14 \mathrm{~mm}$. The root canals were prepared with R25 Reciproc files (VDW, Munich, Germany) and irrigated with $1 \%$ sodium hypochlorite $(\mathrm{NaOCl})$, and the cavities were lubricated with a water-soluble lubricating gel (Endo-PTC Leve; Fórmula e Ação, São Paulo, SP, Brazil). After chemomechanical preparation, final irrigation was performed with $10 \mathrm{~mL}$ of $1 \% \mathrm{NaOCl}, 10 \mathrm{~mL}$ of $17 \%$ EDTA-T, and $10 \mathrm{~mL}$ of $1 \% \mathrm{NaOCl}$. The specimens were obturated with R25 Reciproc gutta-percha cones (VDW, Munich, Germany) and AH Plus sealer (Dentsply, Pennsylvania, USA). The apical $4 \mathrm{~mm}$ of gutta-percha were left in the canal, and the remaining $10 \mathrm{~mm}$ of the root canal were prepared with a \#2 DCR drill of the White Post DCE glass fiber post kit (FGM, Joinville, SC, Brazil), leaving a 10-mm post space.

\section{Randomization of specimens}

The teeth were numbered and randomly divided (www. randomizer.com) into 3 experimental groups of 9 teeth each. In group 1 (control), prefabricated glass fiber posts (FGM, Joinville, SC, Brazil) relined with resin composite (Filtek Z350 XT, 3M ESPE, Brazil) were used- G1 GFRC. In group 2, root canals were scanned for fabrication of intraradicular posts with a CAD/CAM system (Cerec inLab MC XL, Sirona Dental Systems, Inc., NY, USA) using Resin Nano Ceramic (RNC) blocks (Lava ${ }^{\text {TM }}$ Ultimate CAD/CAM Restorative, 3M ESPE, USA)- G2 CAD. In group 3, root canals were scanned for fabrication of intraradicular posts with a CAD/CAM system (Cerec inLab MC XL, Sirona Dental Systems, Inc., NY, USA) using RNC blocks (Lava ${ }^{\text {TM }}$ Ultimate CAD/CAM Restorative, 3M ESPE, USA) and then irradiated with a 940-nm diode laser (Biolase) at $100 \mathrm{~mJ}$, with an optic fiber of $300 \mathrm{um}$ in diameter and helical movements from the coronal to the apical part of the canal and from the apical to the coronal part of the canal at a speed of $2 \mathrm{~mm} / \mathrm{second}$. Each canal was irradiated 4 times- G3 CAD/Laser.

\section{Post preparation and cementation}

All posts were cleaned with alcohol and dried with air spray. Silane was then applied for 1 minute, followed by spray drying and a thin layer of Single Bond Universal adhesive (3M ESPE, Brazil) was applied during 20 seconds without polymerization. The canals were irrigated with $1 \% \mathrm{NaOCl}$ and dried with sterile paper points. A thin layer of Single Bond Universal adhesive (3M ESPE, Brazil) was applied, followed by application of RelyX ${ }^{\mathrm{TM}}$ Ultimate dual cure resin cement (3M ESPE, Brazil) inside the canal. The prepared post was inserted into the root canal and light-cured for 3 seconds. After excess luting material was removed, a final light curing was performed for an additional 40 seconds. 


\section{Mechanical cycling}

The \#2 drill previously used for post space preparation was inserted into the root canal, and the set (root + drill) was placed in the surveyor so that it was tilted at an angle of $135^{\circ}$. The root was fixed inside an acrylic cylinder (diameter of $12 \mathrm{~mm}$ and height of $20 \mathrm{~mm}$ ) by using a high-viscosity crystalline epoxy resin.

For cycling, ceramic copings were manufactured with a CAD/CAM system (IPS emax CAD, Ivoclar Vivadent). They were cleaned with alcohol and dried with air spray, followed by application of silane (Monobond N, Ivoclar Vivadent, Barueri, SP, Brazil) for 1 minute, followed by spray drying for 1 minute. A thin layer of adhesive was applied without polymerization, and the coping was secured on the already cemented post with dual cure resin cement (RelyX'M Ultimate, 3M ESPE, Brazil).

Load was applied at an angle of $135^{\circ}$ to the long axis of the root (figures 1 and 2), with a pulse load of $130 \mathrm{~N}$ and frequency of $2.2 \mathrm{~Hz}$, for a total of 150,000 pulses on the crown at a point located $2 \mathrm{~mm}$ below the incisal edge on the lingual aspect of the specimen.

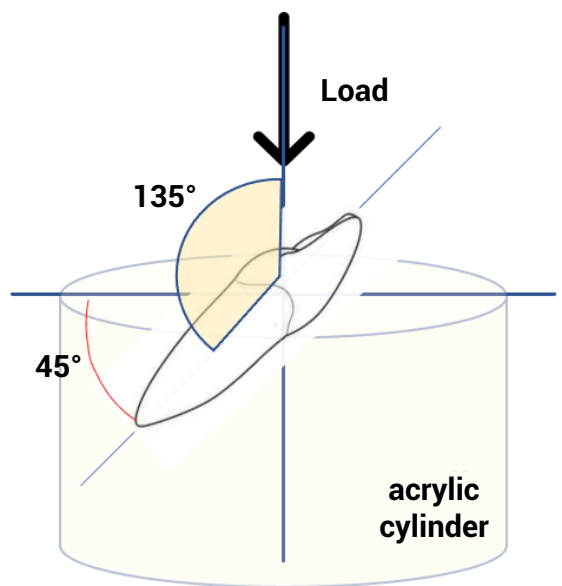

Figure 1. Load was applied at an angle of $135^{\circ}$ to the long axis of the root.

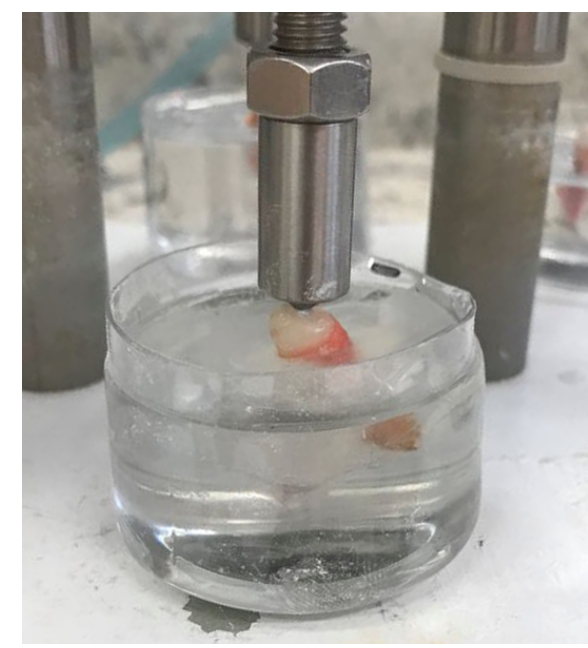

Figure 2. Specimen being cycled in the BiocyclePiopdi cycler (São Carlos, SP, Brazil).

\section{Analysis of specimens}

Every 50,000 cycles, the roots were evaluated by a calibrated observer at $4 \times$ magnification with prismatic loupes (Zeiss EyeMag Pro S, Carl Zeiss). Fractures that occurred in the cementation during the tests were classified as favorable (above $3 \mathrm{~mm}$, which was the simulated bone crest) and unfavorable (below the simulated bone crest).

The collected data was analyzed by one-way ANOVA followed by Tukey's test $(p<0.05)$. 


\section{Results}

Table 1 shows the total number of cycles until fracture occurred. In group 1 (prefabricated glass fiber posts relined with resin composite), fractures occurred just above the simulated alveolar bone crest (favorable) - figure 3. Figure 4 shows a boxplot of the total number of cycles until fracture occurred per experimental group.

Table 1. total number of cycles until fracture occurred

\begin{tabular}{lccc}
\hline Root Fracture & G1 FR & G2 CAD & G3 CAD/Laser \\
\hline 1 & 20000 & 71434 & - \\
\hline 2 & 17148 & - & - \\
\hline 3 & 17853 & - & - \\
\hline 4 & 24926 & - & - \\
\hline 5 & 39779 & - & - \\
\hline 6 & 54230 & - & - \\
\hline 7 & - & - & - \\
\hline 8 & - & - & - \\
\hline
\end{tabular}
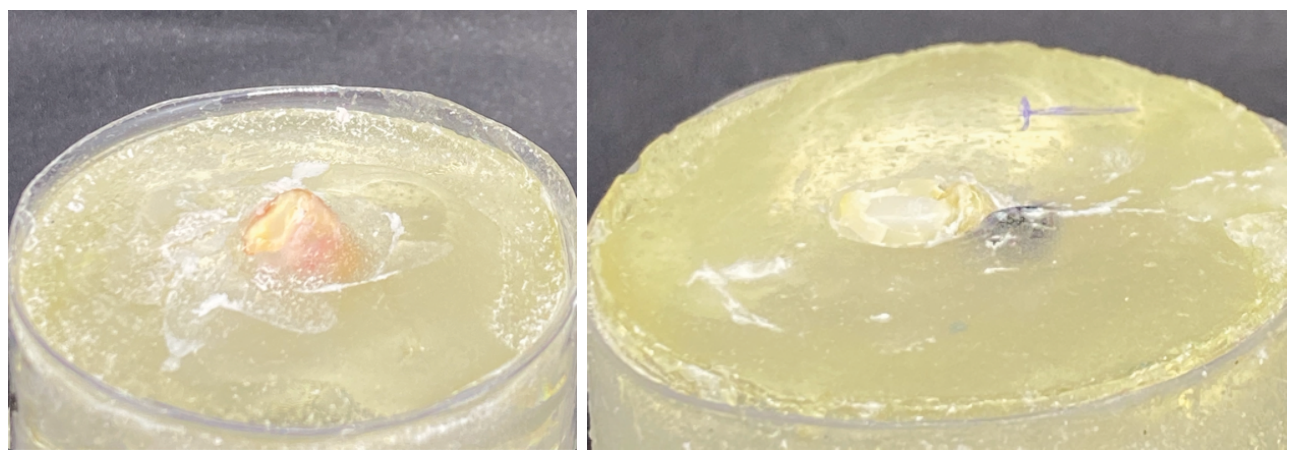

Figure 3. Two specimens above the simulated alveolar bone crest

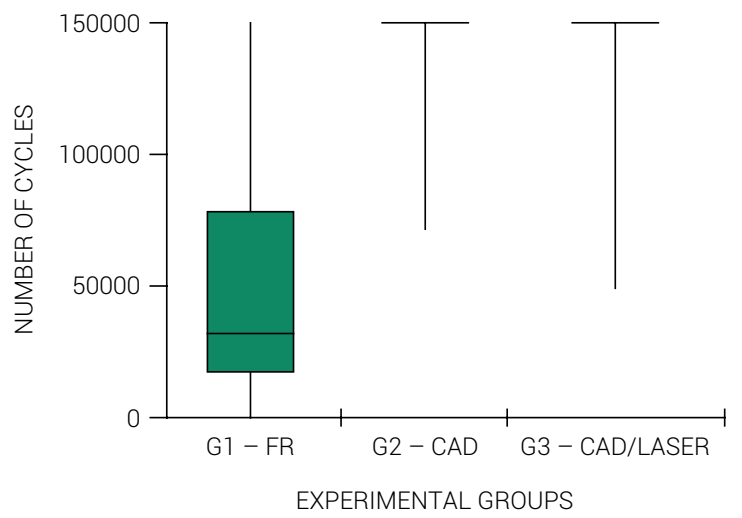

Figure 4. Boxplot of total number of cycles/ fracture. 93 × 67mm (600 x 600 DPI) 
Group 1 was the least resistant, while groups 2 (CAD/CAM-fabricated posts) and 3 (CAD/CAM-fabricated posts in laser-irradiated root canals) were the most resistant. One-way analysis of variance revealed statistically significant differences between the groups $(p<0.01)$, and Tukey's test showed the following results: significant differences between groups 1 and 2 and between groups 1 and $3(p<0.01)$, but no difference between groups 2 and 3 . Groups 2 and 3 showed virtually no fracture in the parameters analyzed. The specimen survival rate (non-fractured roots) was $25 \%$ in group 1 and $87.5 \%$ in groups 2 and 3 (Table 2).

Table 2. specimen survival rate

\begin{tabular}{lccc}
\hline $\begin{array}{l}\text { Specimen } \\
\text { group }\end{array}$ & $\mathbf{G 1}$ & $\mathbf{G 2}$ & $\mathbf{G 3}$ \\
\hline 1 & FR & CAD & CAD/Laser \\
\hline 2 & 20000 & 71434 & 150000 \\
\hline 3 & 17148 & 150000 & 150000 \\
\hline 4 & 17853 & 150000 & 150000 \\
\hline 5 & 24926 & 150000 & 48654 \\
\hline 6 & 39779 & 150000 & 150000 \\
\hline 7 & 54230 & 150000 & 150000 \\
\hline 8 & 150000 & 150000 & 150000 \\
\hline Survival rate & 150000 & 150000 & 150000 \\
\hline & $\mathbf{2 5 \%}$ & $\mathbf{8 7 , 5 \%}$ & $\mathbf{8 7 , 5 \%}$ \\
\hline
\end{tabular}

The specimens number 1 in group 2 and number 4 in group 3 showed fracture of the coping, thereby adversely affecting the test results.

\section{Discussion}

Restoring endodontically treated teeth is challenging due to weakened roots and absence of dental crown or intraradicular dentin ${ }^{17,18}$. Intraradicular posts are commonly indicated to aid in the reconstruction of these elements ${ }^{19}$, but even though irreversible root fracture may still occur, leading to tooth loss. Metal intraradicular posts have a high modulus of elasticity, thus placing greater stress on the remaining root and increasing the risk of fracture ${ }^{20-27}$. For this reason, metal posts were not included in this study.

In vitro $23,28-35$ and clinical ${ }^{21,22,36}$ studies have shown a better performance of prefabricated glass fiber posts when they are relined with resin composite, as this would reduce the amount of cement between the resin and intracanal wall. This justifies the relining of specimens in group 1. However, relining the prefabricated posts with resin composite did not ensure fracture resistance in this group compared to CAD/CAM groups (2 and 3). The rate of non-fractured roots (survival rate) was only $25 \%$. In glass fiber posts, fracture occurs by shear stress when forces are loading at an angle of $45^{\circ}$ to the long axis of the tooth ${ }^{31}$. 
For a long time, prefabricated glass fiber posts have been the posts of choice to restore endodontically treated teeth. However, with the development of the CAD/CAM system, it is possible to fabricate posts that better adapt to the intraradicular canal. These posts are indicated mainly for use in oval or wide canals, in addition to providing a better aesthetic outcome, increased retention, and lower film thickness of the luting cement ${ }^{6,37}$. It is imperative to highlight the increased fracture resistance that the CAD/CAM system provides to the root ${ }^{6,38}$, which supports the choice of this system in the present study. Moreover, the specimen survival rate in groups 2 and 3 was higher than that in group 1, i.e., there was less root fracture - except for the fracture of copings in specimens number 1 and 4 in groups 2 and 3, respectively - which is consistent with the results reported in other studies $5,6,39$.

Several materials can be used in the CAD/CAM system. In the present study, Lava ${ }^{\text {TM }}$ Ultimate RNC was chosen because of its good performance in root fracture resistance tests compared with other materials, according to the results reported by Spina et al. ${ }^{37}$. In addition, according to the manufacturer (3M ESPE, Brazil), this material has a nanoceramic content of $80 \%$, thus providing the benefits of both resin (modulus of elasticity similar to that of dentin) and ceramic (color stability and hardness).

Bond strength is another extremely important factor when investigating intraradicular posts, as well as a determinant of treatment success ${ }^{40-45}$. Dentin-post-cement interactions are influenced by some factors such as integrity of the root canal wall, polymerization of the resin cement, and contamination of the root canal, all of which can increase the risk of root fracture ${ }^{42}$. In the present study, before cementation, the canal walls were examined under an operating microscope and, if impurities were observed in the intracanal wall, they were removed with an XP Endo Finisher rotary file (FKG, Switzerland) aiming to improve cement bonding to the root canal wall.

The significantly superior results obtained with CAD/CAM-fabricated posts (groups 2 and 3 ) over prefabricated glass fiber posts (group 1) were expected by the authors of the present study based on the existing literature. However, a question arose as to whether diode laser treatment of root canals would have a beneficial effect on post bonding to the canal walls and, consequently, on root fracture resistance, since there is a vast literature on the action of diode laser on dentin permeability, smear layer removal, and structural changes in the dentin ${ }^{11,46-49}$, factors closely related to bond strength. This justifies the inclusion of group 3.

Studies with intraradicular surfaces irradiated with a 980-nm diode laser ${ }^{50}$ and Er:YAG, Er,Cr:YSGG ${ }^{51}$ presented an improvement in bond strength of glass fiber posts compared to non-irradiated groups. These findings are in agreement with this study, when group 3 is compared to group 1. However, because bond strength of groups 2 and 3 did not differ significantly, authors can not state that diode laser treatment improved fracture resistance.

The present study performed 150,000 cycles. For more robust results, it will be necessary to manufacture new copings and to continue mechanical cyclic loading until all specimens have fractured, simulating longer time in the mouth, according to other studies ${ }^{37,39}$. Clinical studies are important to validate these in vitro findings. In addition, studies applying different lasers and parameters are required. 
Based on the present results, it can be concluded that CAD/CAM-fabricated intraradicular posts made from Lava ${ }^{\mathrm{TM}}$ Ultimate blocks provided greater fracture resistance of roots than prefabricated glass fiber posts relined with resin composite. Treatment of the intracanal surface with diode laser had no influence on fracture resistance of roots restored with CAD/CAM-fabricated posts, but a longer cycling time is required to evaluate the real benefits of diode laser irradiation.

\section{Author Disclosure Statement}

Financial disclosure: The authors have no financial relationships relevant to this article to disclose.

Conflict of Interest: No competing financial interests exist.

\section{References}

1. Novais VR, Rodrigues RB, Simamoto Junior PC, Lourenco CS, Soares CJ. Correlation between the Mechanical Properties and Structural Characteristics of Different Fiber Posts Systems. Braz Dent J. 2016;27(1):46-51. doi: 10.1590/0103-6440201600377.

2. Barbosa Kasuya AV, Favarão IN, Machado AC, Rezende Spini PH, Soares PV, Fonseca RB. Development of a fiber-reinforced material for fiber posts: Evaluation of stress distribution, fracture load, and failure mode of restored roots. J Prosthet Dent. 2020 Jun;123(6):829-38. doi: 10.1016/j.prosdent.2019.04.026.

3. Pasqualin FH, Giovani AR, De Sousa Neto MD, Paulino SM, Vansan LP. In vitro fracture resistance of glass-fiber and cast metal posts with different designs. Rev Odonto Ciênc. 2012;27(1):52-7. doi: 10.1590/S1980-65232012000100010.

4. Chen A, Feng X, Zhang Y, Liu R, Shao L. Finite element analysis to study the effects of using CAD/ CAM glass-fiber post system in a severely damaged anterior tooth. Biomed Mater Eng. 2015;26 Suppl 1:S519-25. doi: 10.3233/BME-151341.

5. Sary SB, Samah MS, Walid AA. Effect of restoration technique on resistance to fracture of endodontically treated anterior teeth with flared root canals. J Biomed Res. 2019 Apr 22;33(2):131-8. doi: 10.7555/JBR.32.20170099.

6. Pang J, Feng C, Zhu X, Liu B, Deng T, Gao Y, et al. Fracture behaviors of maxillary central incisors with flared root canals restored with CAD/CAM integrated glass fiber post-and-core. Dent Mater J. 2019 Feb 8;38(1):114-9. doi: 10.4012/dmj.2017-394.

7. Garcia PP, da Costa RG, Garcia AV, Gonzaga CC, Cunha LF, Rezende CEE, et al. Effect of surface treatments on the bond strength of CAD/CAM fiberglass posts. J Clin Exp Dent. 2018 Jun 1;10(6):e591-7. doi: 10.4317/jced.54904.

8. Eid R, Azzam K, Skienhe H, Ounsi H, Ferrari M, Salameh Z. Influence of adaptation and adhesion on the retention of computer-aided design/computer-aided manufacturing glass fiber posts to root canal. J Contemp Dent Pract. 2019 Sep;20(9):1003-8.

9. Mannocci F, Bertelli E, Sherriff M, Watson TF, Ford TR. Three-year clinical comparison of survival of endodontically treated teeth restored with either full cast coverage or with direct composite restoration. J Prosthet Dent. 2002 Sep;88(3):297-301. doi: 10.1067/mpr.2002.128492.

10. Mjor IA, Smith MR, Ferrari M, Mannocci F. The structure of dentine in the apical region of human teeth. Int Endod J. 2001 Jul;34(5):346-53. doi: 10.1046/j.1365-2591.2001.00393.x. 
11. Gutknecht N, Alt T, Slaus G, Bottenberg P, Rossel P, Lauwers S, et al. A clinical comparison of the bactericidal effect of the diode laser and $5 \%$ sodium hypochlorite in necrotic root canals. J Oral Laser Applications. 2002;2(3):151-7.

12. Gutknecht N, Franzen R, Meister J, Vanweersch L, Mir M. Temperature evolution on human teeth root surface after diode laser assisted endodontic treatment. Lasers Med Sci. 2005 Sep;20(2):99-103. doi: 10.1007/s10103-005-0347-9.

13. Akyuz Ekim SN, Erdemir A. Effect of different irrigant activation protocols on push-out bond strength Lasers Med Sci. 2015 Nov;30(8):2143-9. doi: 10.1007/s10103-015-1772-z.

14. Borges CC, Palma-Dibb RG, Rodrigues FCC, Plotegher F, Rossi-Fedele G, de Sousa-Neto MD, et al. The Effect of Diode and Er,Cr:YSGG Lasers on the bond strength of fiber posts. Photobiomodul Photomed Laser Surg. 2020 Feb;38(2):66-74. doi: 10.1089/photob.2019.4668.

15. Alonaizan FA, Alofi RS, AlFawaz YF, Alsahhaf A, Al-Aali KA, Vohra F, et al. Effect of Photodynamic Therapy, Er,Cr:YSGG, and Nd:YAG Laser on the push-out bond strength of fiber post to root dentin. Photobiomodul Photomed Laser Surg. 2020 Jan;38(1):24-9. doi: 10.1089/photob.2019.4687.

16. Nasher R, Hilgers RD, Gutknecht N. Debris and Smear Layer Removal in Curved Root Canals Using the Dual Wavelength Er,Cr:YSGG/Diode $940 \mathrm{~nm}$ Laser and the XP-Endoshaper and Finisher Technique. Photobiomodul Photomed Laser Surg. 2020 Mar;38(3):174-80. doi: 10.1089/photob.2019.4693.

17. Erkut S, Eminkahyagil N, Imirzalioglu P, Tunga U. A technique for restoring an overflared root canal in an anterior tooth. J Prosthet Dent. 2004;92:581-3.

18. Yoldas O, Akova T, Uysal H. An experimental analysis of stresses in simulated flared root canals subjected to various post-core applications. J Oral Rehabil. 2004 Dec;92(6):581-3. doi: 10.1016/j.prosdent.2004.08.016.

19. Mitsui FH, Marchi GM, Pimenta LA, Ferraresi PM. In vitro study of fracture resistance of bovine roots using different intraradicular post systems. Quintessence Int. 2004 Sep;35(8):612-6.

20. Silva GR, Santos-Filho PC, Simamoto-Junior PC, Martins LR, Mota AS, Soares CJ. Effect of post type and restorative techniques on the strain and fracture resistance of flared incisor roots. Braz Dent $\mathrm{J}$. $2011 ; 22(3): 230-7$. doi: 10.1590/s0103-64402011000300009.

21. Ferrari M, Vichi A, Garcia-Godoy F. Clinical evaluation of fiber-reinforced epoxy resin posts and cast post and cores. Am J Dent. 2000 May;13(Spec n.):15B-18B.

22. Ferrari M, Cagidiaco MC, Goracci C, Vichi A, Mason PN, Radovic I, et al. Long-term retrospective study of the clinical performance of fiber posts. Am J Dent. 2007 Oct;20(5):287-91

23. Akkayan B, Gulmez T. Resistance to fracture of endodontically treated teeth restored with different post systems. J Prosthet Dent. 2002 Apr;87(4):431-7. doi: 10.1067/mpr.2002.123227.

24. Giovani AR, Vansan LP, de Sousa Neto MD, Paulino SM. In vitro fracture resistance of glassfiber and cast metal posts with different lengths. J Prosthet Dent. 2009 Mar;101(3):183-8. doi: 10.1016/S0022-3913(09)60025-1.

25. Hayashi M, Takahashi Y, Imazato S, Ebisu S. Fracture resistance of pulpless teeth restored with postcores and crowns. Dent Mater. 2006 May;22(5):477-85. doi: 10.1016/j.dental.2005.03.017.

26. Li Q, Yan P, Chen Z. Fracture resistance and failure patterns of open apex root teeth with different posts after endodontic treatment. J Huazhong Univ Sci Technolog Med Sci. 2011 Apr;31(2):271. doi: 10.1007/s11596-011-0265-y.

27. Padmanabhan P. A comparative evaluation of the fracture resistance of three different pre-fabricated posts in endodontically treated teeth: an in vitro study. J Conserv Dent. 2010 Jul;13(3):124-8. doi: 10.4103/0972-0707.71642. 
28. Coelho CS, Biffi JC, Silva GR, Abrahao A, Campos RE, Soares CJ. Finite element analysis of weakened roots restored with composite resin and posts. Dent Mater J. 2009 Nov;28(6):671-8. doi: 10.4012/dmj.28.671.

29. Spazzin AO, Galafassi D, de Meira-Junior AD, Braz R, Garbin CA. Influence of post and resin cement on stress distribution of maxillary central incisors restored with direct resin composite. Oper Dent. 2009;34(2):223-9. doi: 10.2341/08-73.

30. Wandscher VF, Bergoli CD, Limberger IF, Ardenghi TM, Valandro LF. Preliminary results of the survival and fracture load of roots restored with intracanal posts: weakened vs nonweakened roots. Oper Dent. 2014;39(5):541-55. doi: 10.2341/12-465.

31. Wandscher VF, Bergoli CD, de Oliveira AF, Kaiser OB, Borges ALS, Limberguer IF, et al. Fatigue surviving, fracture resistance, shear stress and finite element analysis of glass fiber posts with different diameters. J Mech Behav Biomed Mater. 2015 Mar;43:69-77. doi: 10.1016/j.jmbbm.2014.11.016.

32. Rezaei Dastjerdi M, Amirian Chaijan K, Tavanafar S. Fracture resistance of upper central incisors restored with different posts and cores. Restor Dent Endod. 2015 Aug;40(3):229-35. doi: 10.5395/rde.2015.40.3.229.

33. Rippe MP, Santini MF, Bier CA, Baldissara P, Valandro LF. Effect of root canal preparation, type of endodontic post and mechanical cycling on root fracture strength. J Appl Oral Sci. 2014 Jun;22(3):165-73. doi: 10.1590/1678-775720130051.

34. Pegoretti A, Fambri L, Zappini G, Bianchetti M. Finite element analysis of a glass fibre reinforced composite endodontic post. Biomaterials. 2002 Jul;23(13):2667-82. doi: 10.1016/s0142-9612(01)00407-0.

35. Zamboni SC, Baldissara P, Pelogia F, Bottino MA, Scotti R, Valandro LF. Fatigue resistance of bovine teeth restored with resin-bonded fiber posts: effect of post surface conditioning. Gen Dent. 2008;56(1):56-9.

36. Schmitter M, Rammelsberg P, Gabbert O, Ohlmann B. Influence of clinical baseline findings on the survival of 2 post systems: a randomized clinical trial. Int J Prosthodont. 2007;20(2):173-8.

37. Spina DRF, Da Costa RG, Farias IC, Cunha LG, Ritter AV, Gonzaga CC, et al. CAD/CAM postand-core using different esthetic materials: fracture resistance and bond strengths. Am J Dent. 2017;30(6):299-304.

38. Tsintsadze N, Juloski J, Carrabba M, Tricarico M, Goracci C, Vichi A, et al. Performance of CAD/CAM fabricated fiber posts in oval-shaped root canals: An in vitro study. Am J Dent. 2017;30(5):248-54.

39. Da Costa RG, Freire A, Caregnatto de Morais EC, Machado de Souza E, Correr GM, Rached RN. Effect of CAD/CAM glass fiber post-core on cement micromorphology and fracture resistance of endodontically treated roots. Am J Dent. 2017;30(1):3-8.

40. Silva RA, Coutinho M, Cardozo PI, Silva LA, Zorzatto JR. Conventional dual-cure versus selfadhesive resin cements in dentin bond integrity. J Appl Oral Sci. 2011 Aug;19(4):355-62. doi: 10.1590/s1678-77572011005000010.

41. Menezes MS, Queiroz EC, Campos RE, Martins LR, Soares CJ. Influence of endodontic sealer cement on fibreglass post bond strength to root dentine. Int Endod J. 2008 Jun;41(6):476-84. doi: 10.1111/j.1365-2591.2008.01378.x.

42. Serafino C, Gallina G, Cumbo E, Ferrari M. Surface debris of canal walls after post space preparation in endodontically treated teeth: a scanning electron microscopic study. Oral Surg Oral Med Oral Pathol Oral Radiol Endod. 2004;97:381-7. 2004 Mar;97(3):381-7. doi: 10.1016/j.tripleo.2003.10.004.

43. Goracci C, Corciolani G, Vichi A, Ferrari M. Light-transmitting ability of marketed fiber posts. J Dent Res. 2008 Dec;87(12):1122-6. doi: 10.1177/154405910808701208. 
44. Silva NR, Castro CG, Santos-Filho PC, Silva GR, Campos RE, Soares PV, et al Influence of different post design and composition on stress distribution in maxillary central incisor: finite element analysis. Indian J Dent Res. 2009;20(2):153-8. doi: 10.4103/0970-9290.52888.

45. Oliveira PHC, Oliveira LHC, Cabral MR, Moraes AGV, Sgura R, Cesar PF, et al. Effect of surface treatment with $\mathrm{CO} 2$ laser on bond strength in composite resin restorations. Photobiomodul Photomed Laser Surg. 2019 Jul;37(7):428-33. doi: 10.1089/photob.2018.4534.

46. Lopes FC, Roperto R, Akkus A, Akkus O, Souza-Gabriel AE, Sousa-Neto MD. Effects of different lasers on organic/inorganic ratio of radicular dentin. Lasers Med Sci. 2016 Apr;31(3):415-20. doi: 10.1007/s10103-015-1862-y.

47. Al-Karadaghi TS, Franzen R, Jawad HA, Gutknecht N. Investigations of radicular dentin permeability and ultrastructural changes after irradiation with Er,Cr:YSGG laser and dual wavelength (2780 and $940 \mathrm{~nm}$ ) laser. Lasers Med Sci. 2015 Nov;30(8):2115-21. doi: 10.1007/s10103-015-1757-y.

48. Deleu E, Meire MA, De Moor RJ. Efficacy of laser-based irrigant activation methods in removing debris from simulated root canal irregularities. Lasers Med Sci. 2015 Feb;30(2):831-5. doi: 10.1007/s10103-013-1442-y.

49. Da Costa Ribeiro A, Nogueira GE, Antoniazzi JH, Moritz A, Zezell DM. Effects of diode laser $(810 \mathrm{~nm})$ irradiation on root canal walls: thermographic and morphological studies. J Endod. 2007 Mar;33(3):252-5. doi: 10.1016/j.joen.2006.09.002.

50. Garcia Lda F, Naves LZ, Farina AP, Walker CM, Consani S, Pires-de-Souza FC. The effect of a $980 \mathrm{~nm}$ diode laser with different parameters of irradiation on the bond strength of fiberglass posts. Gen Dent. 2011;59(1):31-7; quiz 38-9, 80

51. Gomes KGF, Faria NS, Neto WR, Colucci V, Gomes EA. Influence of laser irradiation on the push-out bond strength between a glass fiber post and root dentin. J Prosthet Dent. 2018 Jan;119(1):97-102. doi: 10.1016/j.prosdent.2017.01.013. 